\title{
Overview of Therapeutic Ultrasound Applications and Safety Considerations
}

\author{
Douglas L. Miller, PhD, Nadine B. Smith, PhD, Michael R. Bailey, PhD, Gregory J. Czarnota, PhD, MD, \\ Kullervo Hynynen, PhD, Inder Raj S. Makin, MD, PhD; Bioeffects Committee of the American Institute of \\ Ultrasound in Medicine
}

Article includes CME test

Received August 15, 2011, from the Department of Radiology, University of Michigan, Ann Arbor, Michigan USA (D.L.M.); Department of Bioengineering, Penn State University, University Park, Pennsylvania USA (N.B.S. [deceased]); Applied Physics Laboratory, University of Washington, Seattle, Washington USA (M.R.B.); Sunnybrook Research Institute, Sunnybrook Health Science Center, Toronto, Ontario, Canada (G.J.C.); Department of Medical Biophysics, University of Toronto, Toronto, Ontario, Canada (K.H.); and School of Osteopathic Medicine and Arizona School of Dentistry, A. T. Still University, Mesa Arizona USA (I.R.S.M.). Revision requested August 29, 2011. Revised manuscript accepted for publication October 14, 2011.

Address correspondence to Douglas L. Miller, PhD, Department of Radiology, University of Michigan, 3240A Medical Science Building I, 1301 Catherine St, Ann Arbor, MI 48109-5667.

E-mail:douglm@umich.edu

Abbreviations

ESWL, extracorporeal shock wave lithotripsy; FDA, Food and Drug Administration; HIFU, high-intensity focused ultrasound
Applications of ultrasound in medicine for therapeutic purposes have been accepted and beneficial uses of ultrasonic biological effects for many years. Low-power ultrasound of about $1 \mathrm{MHz}$ has been widely applied since the 1950s for physical therapy in conditions such as tendinitis and bursitis. In the 1980s, high-pressure-amplitude shock waves came into use for mechanically resolving kidney stones, and "lithotripsy" rapidly replaced surgery as the most frequent treatment choice. The use of ultrasonic energy for therapy continues to expand, and approved applications now include uterine fibroid ablation, cataract removal (phacoemulsification), surgical tissue cutting and hemostasis, transdermal drug delivery, and bone fracture healing, among others. Undesirable bioeffects can occur, including burns from thermal-based therapies and severe hemorrhage from mechanical-based therapies (eg, lithotripsy). In all of these therapeutic applications of ultrasound bioeffects, standardization, ultrasound dosimetry, benefits assurance, and side-effect risk minimization must be carefully considered to ensure an optimal benefit to risk ratio for the patient. Therapeutic ultrasound typically has welldefined benefits and risks and therefore presents a manageable safety problem to the clinician. However, safety information can be scattered, confusing, or subject to commercial conflicts of interest. Of paramount importance for managing this problem is the communication of practical safety information by authoritative groups, such as the American Institute of Ultrasound in Medicine, to the medical ultrasound community. In this overview, the Bioeffects Committee of the American Institute of Ultrasound in Medicine outlines the wide range of therapeutic ultrasound methods, which are in clinical use or under study, and provides general guidance for ensuring therapeutic ultrasound safety.

Key Words — medical ultrasound devices; therapeutic ultrasound; ultrasound safety

$\bigcup$ ltrasound has seen development not only as a diagnostic imaging modality but also as a therapeutic modality in which energy is deposited in tissue to induce various biological effects. Medical uses of ultrasound for therapy began to be explored in the 1930s. Early applications were tried for various conditions using the mechanism of tissue heating. ${ }^{1}$ Over the following decades, scientific advances allowed improved methods for effective treatment of Meniere disease by destruction of the vestibular nerve and Parkinson disease using focused ultrasound for localized tissue destruction in the brain. ${ }^{2,3}$ By the 1970s, the use of therapeutic ultrasound was established for physiotherapy, and research continued on more difficult applications in neurosurgery ${ }^{4}$ and for cancer treatment. ${ }^{5}$ Subsequently, the development of ther- 
apeutic ultrasound has accelerated, with a wide range of methods now in use. The potent application of ultrasound for therapeutic efficacy also carries the risk of unintentional adverse bioeffects, which can lead to severe, even lifethreatening patient injury. Therefore, standardization, ultrasound dosimetry, benefits assurance, and side-effect risk minimization must be carefully considered to ensure an optimal outcome for the patient.

The purpose of this review is to briefly outline the recent development of therapeutic ultrasound applications and specialized devices, which have been approved for use, together with associated safety considerations. Therapeutic applications of ultrasound may be used clinically after government approval (eg, by the Food and Drug Administration [FDA] in the United States) for marketing suitable treatment devices. A list of therapy applications with FDAapproved devices in clinical use is provided in Table 1 . The fundamental basis behind the ultrasound-mediated deposition of energy and mechanisms for biological effects are discussed, followed by a discussion of ultrasound treatment methods using heating, which include physical therapy, hyperthermia, and high-intensity focused ultrasound (HIFU). Nonthermal applications are then reviewed, including extracorporeal shock wave lithotripsy (ESWL), intracorporeal lithotripsy, and lower-power, kilohertz-frequency ultrasound devices. Some ultrasound therapy methods have uncertain, possibly multiple mechanisms, including skin permeabilization for drug delivery and low-intensity pulsed ultrasound, which can accelerate the healing of bone fractures. Prospective new methods of therapeutic ultrasound are mentioned at the end, including new microbubble- or cavitation-based treatment methods. Last, the reader is reminded of important safety considerations, and general guidelines are presented. There is no

Table 1. Food and Drug Administration—Approved Modes for Ultrasound Therapy

\begin{tabular}{|c|c|c|c|c|c|c|}
\hline \multirow{2}{*}{$\begin{array}{l}\text { Therapy } \\
\text { Method }\end{array}$} & \multirow{2}{*}{$\begin{array}{l}\text { Therapeutic } \\
\text { Outcome }\end{array}$} & \multirow{2}{*}{$\begin{array}{c}\text { Bioeffect } \\
\text { Mechanism }\end{array}$} & \multicolumn{3}{|c|}{ Device Characteristics } & \multirow{2}{*}{$\begin{array}{l}\text { General } \\
\text { Reference }\end{array}$} \\
\hline & & & Applicator & Frequency & Delivery & \\
\hline Unfocused beam & Tissue warming & Heating & Portable handheld & $1-3 \mathrm{MHz}$ & $\begin{array}{l}\text { Continuous or } \\
\text { repeated bursts }\end{array}$ & $\begin{array}{l}\text { Robertson and } \\
\text { Baker }{ }^{6}\end{array}$ \\
\hline Hyperthermia & Cancer therapy & Regional heating & Multielement applicator & $1-3.4 \mathrm{MHz}$ & $1 \mathrm{~h}$ & Samulski et al ${ }^{7}$ \\
\hline $\begin{array}{l}\text { High-intensity } \\
\text { focused ultrasound }\end{array}$ & $\begin{array}{l}\text { Uterine fibroid } \\
\text { ablation }\end{array}$ & Thermal lesion & Computer directed & $0.5-2 \mathrm{MHz}$ & Long bursts & Tempany et al ${ }^{8}$ \\
\hline \multirow{2}{*}{$\begin{array}{l}\text { High-intensity } \\
\text { focused ultrasound }\end{array}$} & & & & & & \\
\hline & Glaucoma relief & Permeabilization & $\begin{array}{l}\text { Fixed probe with water } \\
\text { bath }\end{array}$ & $4.6 \mathrm{MHz}$ & $1-3 s$ & Burgess et al ${ }^{9}$ \\
\hline $\begin{array}{l}\text { High-intensity } \\
\text { focused ultrasound }\end{array}$ & $\begin{array}{l}\text { Laparoscopic tissue } \\
\text { ablation }\end{array}$ & Thermal lesion & Handheld & $4 \mathrm{MHz}$ & Long bursts & Klingler et al ${ }^{10}$ \\
\hline $\begin{array}{l}\text { High-intensity } \\
\text { focused ultrasound }\end{array}$ & $\begin{array}{l}\text { Laparoscopic or } \\
\text { open surgery }\end{array}$ & Thermal lesion & Handheld & $3.8-6.4 \mathrm{MHz}$ & Long bursts & Ninet et al ${ }^{11}$ \\
\hline Focused ultrasound & Skin tissue tightening & Thermal lesion & $\begin{array}{l}\text { Handheld, imaging } \\
\text { and treatment }\end{array}$ & 4.4-7.5 MHz & $\begin{array}{l}\text { 20-to } 50-m s \\
\text { bursts }\end{array}$ & Alam et al ${ }^{12}$ \\
\hline $\begin{array}{l}\text { Extracorporeal } \\
\text { lithotripsy }\end{array}$ & $\begin{array}{l}\text { Kidney stone } \\
\text { comminution }\end{array}$ & $\begin{array}{l}\text { Mechanical stress, } \\
\text { cavitation }\end{array}$ & $\begin{array}{l}\text { Mainframe with } \\
\text { image guidance }\end{array}$ & $\approx 150 \mathrm{kHz}$ & Shock waves & Weizer et al ${ }^{13}$ \\
\hline $\begin{array}{l}\text { Intracorporeal } \\
\text { lithotripsy }\end{array}$ & $\begin{array}{l}\text { Kidney stone } \\
\text { comminution }\end{array}$ & $\begin{array}{l}\text { Mechanical stress, } \\
\text { cavitation }\end{array}$ & $\begin{array}{l}\text { Percutaneous } \\
\text { probes }\end{array}$ & $25 \mathrm{kHz}$ & Continuous & $\begin{array}{l}\text { Lowe and } \\
\text { Knudsen }^{14}\end{array}$ \\
\hline $\begin{array}{l}\text { Extracorporeal } \\
\text { shock wave therapy }\end{array}$ & $\begin{array}{l}\text { Plantar fasciitis, } \\
\text { epicondylitis }\end{array}$ & Unknown & $\begin{array}{l}\text { Mainframe with } \\
\text { applicator head }\end{array}$ & $\approx 150 \mathrm{kHz}$ & Shock waves & Haake et a $1^{15}$ \\
\hline Phacoemulsification & Lens removal & $\begin{array}{l}\text { Vibration, } \\
\text { cavitation }\end{array}$ & Generator with probe & $40 \mathrm{kHz}$ & Continuous & Packer et a $1^{16}$ \\
\hline $\begin{array}{l}\text { Ultrasound-assisted } \\
\text { liposuction }\end{array}$ & $\begin{array}{l}\text { Adipose tissue } \\
\text { removal }\end{array}$ & $\begin{array}{l}\text { Fat liquefaction, } \\
\text { cavitation }\end{array}$ & Generator with probe & $20-30 \mathrm{kHz}$ & Continuous & Mann et al ${ }^{17}$ \\
\hline $\begin{array}{l}\text { Tissue cutting and } \\
\text { vessel sealing }\end{array}$ & $\begin{array}{l}\text { Laparoscopic or } \\
\text { open surgery }\end{array}$ & $\begin{array}{l}\text { Thermal lesion, } \\
\text { vibration }\end{array}$ & Handheld & $55.5 \mathrm{kHz}$ & Continuous & Koch et al ${ }^{18}$ \\
\hline $\begin{array}{l}\text { Intravascular } \\
\text { ultrasound }\end{array}$ & Thrombus dissolution & $\begin{array}{l}\text { Unknown, gas } \\
\text { body activation }\end{array}$ & Intravascular catheter & $2.2 \mathrm{MHz}$ & Continuous & Parikh et a $1^{19}$ \\
\hline $\begin{array}{l}\text { Skin perm- } \\
\text { eabilization }\end{array}$ & $\begin{array}{l}\text { Transdermal drug } \\
\text { delivery }\end{array}$ & Unknown & Handheld & $55 \mathrm{kHz}$ & Continuous & Smith $^{20}$ \\
\hline $\begin{array}{l}\text { Low-intensity pulsed } \\
\text { ultrasound }\end{array}$ & Bone fracture healing & Unknown & Attached transducer & $1.5 \mathrm{MHz}$ & $\begin{array}{l}\text { Pulsed, long } \\
\text { duration }\end{array}$ & Gebauer et al ${ }^{21}$ \\
\hline
\end{tabular}


doubt that continued biophysical discoveries in ultrasound will lead to new treatments and applications. As therapeutic ultrasound's renaissance continues, new treatments already well established in the laboratory will be translated in the near future to the clinic.

\section{The Biophysical Bases for Therapeutic Ultrasound Applications}

Ultrasonic energy can be a potent modality for generating biological effects. Given sufficient knowledge of the etiology and exposimetry, bioeffects can be planned for therapeutic purposes or avoided in diagnostic applications. For therapy, ultrasound can induce effects not only through heating but also through nonthermal mechanisms, including ultrasonic cavitation, gas body activation, mechanical stress, and other undetermined nonthermal processes. ${ }^{22}$

Starting from the diagnostic reference frame, ultrasound is usually produced from a piezoceramic crystal in very short, ie, 1- to 5-cycle, pulses. Diagnostic ultrasound is often characterized by the center frequency of the pulses (typically in the 2- to $12-\mathrm{MHz}$ range), which is usually a frequency inherent to the thickness of the ceramic crystal. As the pressure amplitude, the frequency, or the propagation length is increased, the ultrasound wave can distort, which could ultimately lead to a discontinuity or shock in the waveform. With regard to bioeffects, increasing the frequency, nonlinear acoustic distortion, or pulse length can increase heating and enhance some nonthermal mechanisms, eg, radiation force. Decreasing the frequency increases the likelihood of cavitation and gas body activation. Increasing the power or intensity tends to increase the likelihood and magnitude of all bioeffects mechanisms. Therapeutic ultrasound devices may use short bursts or continuous waves to deliver effective ultrasonic energy to tissues. Some devices operate at higher amplitudes and therefore tend to produce shocked or distorted waves.

Ultrasound-induced heating is the result of the absorption of ultrasonic energy in biological tissue. For diagnostic ultrasound, temperature elevations and the potential for bioeffects are kept relatively low or negligible $\mathrm{e}^{23}$ by carefully described indications for use, applying the ALARA (as low as reasonably achievable) principal, limited temporal average intensities, and generally short exposure durations. Therapeutic applications of ultrasonic heating therefore either use longer durations of heating with unfocused beams or use higher-intensity (than diagnostic) focused ultrasound. The use of unfocused heating, for example, in physical therapy to treat highly absorbing tissues such as bone or tendon, can be moderated to produce en- hanced healing without injury. Alternatively, the heat can be concentrated by focused beams until tissue is coagulated for the purpose of tissue ablation. Ultrasonic heating, which can lead to irreversible tissue changes, follows an inverse time-temperature relationship. Depending on the temperature gradients, the effects from ultrasound exposure can include mild heating, coagulative or liquefactive necrosis, tissue vaporization, or all three.

Ultrasonic cavitation and gas body activation are closely related mechanisms, which depend on the rarefactional pressure amplitude of ultrasound waves. Ultrasound transmitted into a tissue may have rarefactional pressure amplitudes of several megapascals. This tensile stress is supported by the medium, and, for example, a 2-MPa rarefactional pressure, which is common even for diagnostic ultrasound, represents a negative tension 20 times the atmospheric pressure (ie, $0.1 \mathrm{MPa}$ ). This high rarefactional pressure can act to initiate cavitation activity in tissue when suitable cavitation nuclei are present or directly induce pulsation of preexisting gas bodies, such as occur in lung and intestine or with ultrasound contrast agents. Cavitation and gas body activation primarily cause local tissue injury in the immediate vicinity of the cavitational activity, including cell death and hemorrhage of blood vessels.

Other potential mechanisms for biological effects of ultrasound include the direct action of the compressional, tensile, and shear stresses. In addition, second-order phenomena, which depend on transmitted ultrasonic energy, include radiation pressure, forces on particles, and acoustic streaming. For high-power or high-amplitude ultrasound for therapy, several different mechanisms may be contributing concurrently to the total biological impact of the treatment. In addition to direct physical mechanisms for bioeffects, there are secondary physical, biological, and physiologic mechanisms that cause further impact on the organism. Some examples are vasoconstriction, ischemia, extravasation, reperfusion injury, and immune responses. ${ }^{24-26}$ Sometimes these secondary effects are greater than the direct insult from the ultrasound.

\section{Therapeutic Applications of Ultrasound Based on Heating}

\section{Physical Therapy}

Unfocused beams of ultrasound for physical therapy were the first clinical application, dating to the 1950s, which often has been referred to simply as "therapeutic ultrasound." This modality now typically has a base unit for generating an electrical signal and a handheld transducer. The handheld transducer is applied with coupling gel and 
moved in a circular motion over an injured or painful area of the anatomy to treat conditions such as bursitis of the shoulder and tendonitis by trained physical therapy technicians. The objective is to warm tendons, muscle, and other tissue to improve blood flow and accelerate healing. The coupling medium can also include various compounds for enhancing the treatment. Ultrasound application can assist by promoting transport of the compound into the skin, a method sometimes called sonophoresis or phonophoresis (as opposed to electrophoresis). ${ }^{27}$ Drugs, such as lidocaine and cortisol, have been used extensively in sports medicine. The level of clinical benefit to the patient from physical therapy ultrasound treatments remains uncertain. ${ }^{6,28,29}$ However, the risk of harm, such as burns, appears to be low when the modality is properly applied. Overall, ultrasound for physical therapy has therefore provided a modest level of efficacy and patient benefit but also a low level of risk.

\section{Hyperthermia}

A substantial effort during the 1980s and 1990s sought to develop means to ultrasonically heat relatively large volumes of tissue for the purpose of cancer therapy. This method of hyperthermia involves uniformly heating a tumor to about $42^{\circ} \mathrm{C}$ to $45^{\circ} \mathrm{C}$ for about 30 to 60 minutes, which appears to be effective in reducing tumor growth. ${ }^{30}$ Multielement applicators have been used at 1 to $3.4 \mathrm{MHz} .^{7,31}$ In clinical trials, hyperthermia was used with or without radiation therapy, and modest efficacy has been reported. ${ }^{32}$ Research suggests that hyperthermia may be advantageous for drug delivery treatment using nanoparticles. ${ }^{33}$ However, the moderatetemperature hyperthermia method has not progressed to widespread clinical use, and the effort in hyperthermia cancer treatment has shifted to the use of HIFU.

\section{High-Intensity Focused Ultrasound}

High-intensity focused ultrasound was initially studied clinically for thermal ablation of inoperable brain tissue for Parkinson disease. ${ }^{2,34}$ In an HIFU system, a signal generator is connected to a focusing transducer, which produces very high local intensities of greater than $1 \mathrm{~kW} / \mathrm{cm}^{2}$ of 0.5 - to $7-\mathrm{MHz}$ ultrasound at the focal spot. The lesion produced in tissue typically may be a few millimeters in diameter and length. The position of this spot must be carefully controlled and moved to ablate larger volumes of tissue. This method is approved by the FDA in the United States for treating uterine fibroids, ${ }^{8}$ cardiac ablation, ${ }^{11}$ visceral soft tissue ablation, ${ }^{10}$ and aesthetic treatment to lift the eyebrow. ${ }^{12,35}$ In addition, a method was developed and was approved for treatment of glaucoma using HIFU. ${ }^{9}$
In addition to the devices approved by the FDA for clinical use, there are several procedures that are being investigated for clinical application. ${ }^{36}$ High-intensity focused ultrasound application in therapy and treatment of disease is one of the more active areas of research and development among all of the nonionizing energy modalities such as radiofrequency, lasers, and microwaves. For example, HIFU is under investigation for therapeutic modulation of nerve conductance. ${ }^{37}$ Among other applications, the oldest and possibly the most investigated area (particularly outside the Unites States) is the treatment of benign prostatic hyperplasia and the treatment of prostate cancer using HIFU. A number of multicenter and systematic studies with several-year follow-up have established the use of HIFU as a viable option for the management of prostate cancer. ${ }^{38,39}$

A key element of therapeutic applications of ultrasonic energy is the capability to focus energy several millimeters to centimeters away from the transducer plane. It is, therefore, very important to accurately determine the location of the treatment zone with ultrasound systems. Furthermore, the tissue changes in the treatment zone must be reliably monitored to confirm that adequate treatment has been achieved. The focused ultrasound beam can then be moved to a different location to complete the treatment of the planned volume. Two methods used for image guidance and treatment monitoring are magnetic resonance imaging and ultrasound imaging. Magnetic resonance imaging can measure temperature changes during therapy, within the treatment zone of therapeutic ultrasound procedures. ${ }^{40}$ Specialized clinical systems have ultrasound therapy subsystems integrated into magnetic resonance scanners, which are used for uterine fibroid treatment ${ }^{8}$ and brain, ${ }^{41,42}$ breast, ${ }^{43,44}$ bone, ${ }^{45}$ liver, ${ }^{46}$ and prostate cancer management. ${ }^{47}$ Ultrasound-based guidance and monitoring offer the possibility of systems that incorporate both the treatment and imaging modality in one compact system. Ultrasound image monitoring of tissue changes during ultrasound therapy is still under development, and some of the possible methods are based on a combination of the speed of sound, attenuation, stiffness, and vapor content changes in the target region, ${ }^{48-}$ 51 including boiling detection. 52

In addition to external focused devices, a number of other devices and systems are being developed for soft tissue coagulation, which are primarily used in noninvasive approaches: percutaneously for interstitial liver tissue ablation ${ }^{53}$ or through natural orifices such as the transrectal approach for prostate treatments. ${ }^{38}$ For example, transurethral ultrasound has been proposed for heating the prostate ${ }^{47,54}$; endoscopic treatment with an intraductal ultrasound probe 
has been used to treat bile duct tumors ${ }^{55}$; and an intravascular approach has been used for cardiac ablation. ${ }^{56}$

Considerable research and development are being pursued in the area of noninvasive aesthetic applications. Focused ultrasound in these applications is directed within the first 2 to $20 \mathrm{~mm}$ of the skin and subcutaneous tissue (dermis to subcutaneous fat). Very small lesions of approximately $1 \mathrm{~mm}^{3}$ up to several tens of cubic centimeters can be produced. The approach may provide a safer alternative to liposuction for cosmetic applications. ${ }^{57}$ Superficial tissue is exposed to HIFU, leading either to a contraction of collagen-based tissue (dermis) or to destruction of adipose tissue. ${ }^{35,58} \mathrm{~A}$ clinical system has been approved for fat debulking in the European Union and Canada. ${ }^{59}$ Depending on the device, as well as the cosmetic application, both thermal and nonthermal mechanisms within an ultrasonic field are used for these procedures. One of these devices is currently approved for clinical use in the United States, ${ }^{12}$ and others are in use worldwide. Long-term use of this technology, as well as regulatory approval, is still evolving.

High-intensity focused ultrasound applications involve delivery of substantial ultrasonic energy to localized areas, and undesired tissue injury is always a consideration. Typically, unwanted burns and pain can occur. In addition, HIFU can cause vasospasms and hemorrhage under conditions that generate concomitant cavitation in tissue. ${ }^{60}$ Other substantial bioeffects and complications can also occur, with unique risk-benefit considerations for each application. Treatment of the prostate, such as for prostate cancer, can lead to several urologic complications, including impotence and incontinence, ${ }^{61}$ which can also accompany other types of treatment for prostate cancer. High-intensity focused ultrasound has been used to treat atrial fibrillation by tissue ablation to produce pulmonary vein isolation. However, severe complications can occur due to creation of an atrial-esophageal fistula, ${ }^{62}$ a concern that is difficult to eliminate. ${ }^{63}$ Treatment of hepatic and pancreatic cancer can also lead to serious complications, including fistula formation and rib necrosis with delayed rib fracture. ${ }^{64}$ Detailed safety considerations should accompany the introduction of HIFU applications into clinical practice to ensure a benefit while minimizing risk to the patient.

\section{Therapeutic Applications of Ultrasound Based on Nonthermal Mechanisms}

\section{Extracorporeal Shock Wave Lithotripsy}

Extracorporeal shock wave lithotripsy is a widely used ultrasound therapy, which relies on nonthermal mechanisms for its efficacy. ${ }^{13,65}$ When introduced in the 1980 s, lithotripsy gained rapid acceptance and became the dominant treatment method. Shock wave devices similar to lithotripters are approved and marketed for orthopedic indications such as plantar fasciitis and epicondylitis. ${ }^{15}$ The use of shock waves for treating other problems, such as gallbladder stones, has also been explored, but none have achieved widespread usage. Over 50 lithotripter devices have been on the US market. Fluoroscopy is used for targeting the acoustic focus on the stone in the United States, although some lithotripters have B-mode ultrasound for targeting. The first lithotripters were electrohydraulic, using an underwater spark source and a reflector. Most lithotripters now are of the electromagnetic design, which deposits a high transient current through a coil that in turn produces displacement of a plate. Very few lithotripters use piezoceramic sources. All produce about the same waveform: a 1-microsecond shocked spike of about 50 $\mathrm{MPa}$ followed by an approximately 10-MPa, 4-microsecond negative pressure tail. The center frequency might be estimated to be about $150 \mathrm{kHz}$, although it is not a commonly determined parameter. There was a trend to more focused machines, relative to early spark gap models, but that has fallen out of favor. Evidence has been presented for a reduction in clinical effectiveness and safety for highly focused shock waves ${ }^{65}$ and for the dependence of fragmentation mechanisms on the beam width. ${ }^{66,67}$

For ESWL treatment, the source is coupled to the patient by a water pillow and transmission gel and in the remaining original lithotripters through a water bath. Coupling has recently been recognized as an important factor in ESWL treatment efficacy; a point that has implications across therapeutic ultrasound. ${ }^{68}$ About 3000 shock waves are triggered at about a $2-\mathrm{Hz}$ repetition rate to pulverize the stone so that the pieces $(<2 \mathrm{~mm})$ can pass naturally in urine. The prominent mechanism is the wave running over the stone, creating shear waves to tear the stone apart from within. Cavitation chips away from the outside, adding cracks that grow by dynamic fatigue and further grind down the stone to a passable size. ${ }^{67}$

Lithotripsy has several important biological side effects. It causes injury to virtually all patients. ${ }^{69}$ Blood vessel walls break, and there is bleeding into the connective tissue interstitium, which can result in bruising of the parenchyma or the formation of massive subcapsular hematomas. Inflammation ensues (ie, lithotripsy nephritis), which can lead to scar formation ${ }^{70}$ and permanent loss of functional renal mass. ${ }^{71}$ In addition to and likely a result of this direct injury cascade, lithotripsy can lead to an accelerated rise in systemic blood pressure, a decrease in 
renal function, onset of hypertension, an increase in the rate of stone recurrence, and an exacerbation of stone disease. ${ }^{72,73} \mathrm{~A}$ single retrospective study has linked lithotripsy and diabetes mellitus. ${ }^{74}$

The risks of these adverse bioeffects in lithotripsy have stimulated investigation into mitigation methods with some success. ${ }^{65}$ For example, a slower repetition rate (1 $\mathrm{Hz}$ ) is safer and more effective than the common fast rate $(2 \mathrm{~Hz}){ }^{75}$ and a pause early in treatment nearly eliminates injury in animals. ${ }^{13,76}$ Overall, lithotripsy has been a therapeutic ultrasound method with a high level of efficacy and patient benefits but also some important risks, particularly for patients requiring repeated treatments. The development of safer treatment protocols for lithotripsy is a prime example of the potential value of research on risk mitigation for optimizing the patient risk-benefit profile in therapeutic ultrasound.

\section{Intracorporeal Lithotripsy}

Lithotripsy is also accomplished by minimally invasive probes, which are advanced to the stone. Intracorporeal lithotripsy is the favored treatment for many patients, for example, for very large stones, and many different methods and techniques have been reported. The stone may be imaged for guidance by external ultrasound imaging or fluoroscopy or by ureteroscopic, endoscopic, or laparoscopic methods. Rigid probes may be manipulated percutaneously, but some flexible probes can be applied via the ureter. Rigid ultrasound probes can use both pneumatic action at a few hertz to $1000 \mathrm{~Hz}$ and ultrasonic action at about $25 \mathrm{kHz}{ }^{14,77}$ Electrohydraulic probes, which generate a vaporous cavity at the tip (similar to the spark gap external lithotripter but without focusing), ${ }^{78}$ have been used in the past. Intracorporeal lithotripsy carries risks of hemorrhage, ureteral perforation, urinary tract trauma, and infection due to the invasive nature of the procedures.

\section{Kilohertz-Frequency Ultrasound Devices}

Ultrasound systems operating in the kilohertz frequency regime $(20-90 \mathrm{kHz})$, similar to "sonicators" used in biological research to break up cells and tissues, are used routinely in general and advanced surgical procedures for tissue cutting and hemostasis as well as for tissue removal. These systems appear to act primarily though localized biophysical effects close to the probe tip, rather than via radiated ultrasound waves. For example, a kilohertzfrequency ultrasound probe is used for phacoemulsification to remove the lens of the eye during surgery for cataracts..$^{16}$ The probe appears to mechanically chop up the lens, possibly aided by ultrasonic cavitation, with the lens debris removed by suction through the probe. The procedure is well established in ophthalmology and minimizes the impact on the lens capsule.

Surgical ultrasound instruments, known as "harmonic scalpels," have a 40 - to $80-\mathrm{kHz}$ vibrating titanium rod with a static clamp member, between which the tissue (and blood vessels) is rapidly coagulated due to localized frictional heating. ${ }^{18}$ Another procedure, ultrasound-assisted liposuction, is widely used in cosmetic surgery for the purpose of removing excessive fat tissue. ${ }^{17}$ The mechanism of action apparently involves cavitational fat cell breakup with removal of the fat emulsion by suction through the probe. This procedure is invasive and can lead to complications such as bleeding, scarring, and infection.

\section{Therapeutic Applications of Ultrasound With Multiple Mechanisms}

\section{Catheter-Based Ultrasound}

Intravascular catheters have been developed with megahertz-frequency ultrasound transducers placed near the tip for enhancing dissolution of thrombi. ${ }^{19}$ The catheter is placed into a deep vein thrombus, and the ultrasound is directed radially into the thrombus. In addition, there are provisions for infusion of thrombolytic drugs, such as tissue plasminogen activator. The ultrasound accelerates the action of the thrombolytic drugs so that the total infusion doses of drugs and treatment times can be reduced substantially. The role of this method and the full range of its clinical usefulness for thrombolysis are still being evaluated.

\section{Skin Permeabilization}

For transdermal drug delivery, the stratum corneum $(\approx 10$ $30 \mu \mathrm{m}$ in thickness) forms a barrier to passive drug diffusion for molecules that have a weight of greater than 500 Da. ${ }^{79}$ One effect of low-frequency ultrasound $(<100 \mathrm{kHz})$ is its ability increase permeability of the stratum corneum, which is considered a primary barrier to protein diffusion. ${ }^{80,81}$ The treatment can be monitored by measuring the electrical skin conductance. ${ }^{82}$ Once a drug has traversed the stratum corneum, the next layer is easier to cross, and subsequently the drug can reach the capillary vessels to be absorbed. ${ }^{83}$ This skin permeabilization method may be useful for avoiding the multiple use of needles, for example, for delivery of heparin or insulin through the skin. ${ }^{20}$

\section{Low-Intensity Pulsed Ultrasound}

Low-intensity pulsed ultrasound has therapeutic applications to accelerate the healing of bone fractures, including cases of nonunion. ${ }^{21}$ The characteristics of the pulsed ul- 
trasound, for example, a $1.5-\mathrm{MHz}$ frequency with a $30-$ $\mathrm{mW} / \mathrm{cm}^{2}$ spatial-average temporal-average intensity, are in the range of diagnostic ultrasound. The biophysical mechanisms for the therapeutic action are uncertain for this application. Therapy involves multiple treatments of 20 minutes each day by applying a large flat transducer to the site of injury and continuing treatment for periods of months. Although the process appears to be safe and effective, the therapy is slow, and its use is predominantly limited to management of nonhealing fractures.

\section{Prospective New Methods of Therapeutic Ultrasound}

In this era of ultrasound research, several new means of applying ultrasound for therapy are undergoing intensive research and development. The novel methods use lowfrequency, moderate-power ultrasound aided by stabilized microbubbles for gas body activation or very high-power pulsed ultrasound with vigorous cavitation.

Direct sonothrombolysis using external, typically lowfrequency ultrasound has been tested for treatment of thrombotic disease such as stroke. ${ }^{84}$ This new strategy shows promise but also has shown a potential for deleterious side effects. For example, increased symptomatic brain hemorrhage was found in a clinical trial for treatment with $300-\mathrm{kHz}$ ultrasound plus tissue plasminogen activator relative to treatment with tissue plasminogen activator alone ${ }^{85}$ Recent work suggests that microbubbles enhance thrombolysis and may be of value in improving stroke therapy. ${ }^{86}$

Another potential application in the brain uses transcranial pulsed ultrasound $(0.25-0.5 \mathrm{MHz})$ at relatively low levels (spatial-peak temporal-average intensity, 26-163 $\mathrm{mW} / \mathrm{cm}^{2}$ ) to produce cortical and hippocampal stimulation in mice. ${ }^{87}$ Because measured temperature gradients were less than $0.01^{\circ} \mathrm{C}$, nonthermal mechanisms for the neuronal effects were hypothesized.

Microbubble-based therapeutic strategies are under study for ultrasound-directed and targeted therapy. In these strategies, the external ultrasound exposure activates microbubbles in the circulation, which may also act as drug carriers, at a desired site of treatment. Microbubble contrast agents have also found applications in improving the therapeutic efficacy of biologically active molecules. ${ }^{88} \mathrm{Sev}$ eral possible mechanisms include (1) enhancement of the concentration of therapeutic biomolecules in the vascular compartment of the target area, (2) increased therapeutic agent delivery by extravasation through blood vessels, and (3) potentially enhanced intracellular delivery. Mol- ecules of the therapeutic agent can be attached to the outer shells of bubbles, incorporated within the bubble shells, or loaded in the interior of the microbubbles and released in the vascular compartment through ultrasoundinduced microbubble disruption. ${ }^{89,90}$ The extravasation of a therapeutic agent is achieved through the permeabilization of blood vessels with ultrasound and microbubbles, for example, to cross the blood-brain barrier. ${ }^{91}$ The ultrasound microbubble-based delivery of therapeutic agents has one main advantage over other techniques using colloidal drug carriers such as nanoparticles or liposomes: the microbubble-based technique may be targeted through the external control of the ultrasound. This localized approach may then improve the therapeutic efficacy of drugs, including routinely used chemotherapeutic agents such as paclitaxel. The dose of the agent to normal tissue is lowered, with a consequent minimization of unwanted drug effects away from the treatment site. ${ }^{92}$ At the cellular level, ultrasound with microbubbles can be used to transiently permeabilize cell membranes, allowing transfer of large molecules into the cells. DNA transfer has been shown in extensive research on gene therapy applications. ${ }^{93}$

The cavitation mechanism is also being exploited to create a new tissue ablation method known as histotripsy. ${ }^{94}$ In histotripsy (akin to lithotripsy pulses but at a higher frequency), very high-amplitude ultrasound pulses typically of less than 50 microseconds' duration at $750 \mathrm{kHz}$ create a cavitation microbubble cloud to homogenize targeted tissue such as tumors with little heating. ${ }^{95}$ Longer HIFU pulses (eg, $>3$ milliseconds at $2 \mathrm{MHz}$ ) of very high intensity can induce rapid heating and also generate cavitation and boiling with vapor bubbles that expand very rapidly, thus disrupting tissue. ${ }^{46}$

Because cavitation is a mechanism secondary to the ultrasound exposure, the problems of dosimetry and control are challenging. Determining the energy deposited by ultrasound with cavitation is difficult under the best of circumstances. ${ }^{96,97}$ For cavitating ultrasound, researchers try to follow 3 rules: (1) understand the medium (including cavitation nuclei); (2) understand the sound field; and (3) know when a cavitation effect happens. ${ }^{96}$ The first rule refers to the cavitation threshold, whereas the second rule relates to accurate measurements of the acoustic field. The third relates to observable cavitation events or secondary related information that can be monitored. There are various reliable and scientifically established methods for quantifying an acoustic field. ${ }^{98-101}$ Passive detection methods, measuring broadband acoustic noise from bubble collapse for monitoring cavitation activity, can be deployed, and research has indicated useful dosimetric parameters 
that may be derived for predicting bioeffects. ${ }^{102,103}$ As new cavitation-based treatments are developed, new means for cavitation dosimetry and control will be needed to ensure optimum patient safety.

\section{General Guidance for Therapeutic Ultrasound Safety}

Therapeutic ultrasound methods provide a substantial armamentarium for medical practice. In addition, ultrasound brings fundamentally favorable safety characteristics to the clinic. For example, ionizing radiation with its dose accumulation and cancer risk is absent from ultrasound methods. Low-energy exposures, below the threshold for a bioeffect, do not accumulate to produce the effect, even if repeated many times. The ultrasound waves are dispersed and poorly transmitted in air: no lead gloves, aprons, or other protective gear are needed for ultrasound diagnosis or therapy. However, this powerful modality does require attention to several safety factors to achieve the optimum risk to benefit ratio.

\section{Operator Safety}

The operator of the equipment, for the most part, has little risk of harm from the machines and can remain in the treatment room and safely apply the ultrasound with handheld applicators for some applications. However, simple precautions should be followed for complete operator safety; for example, do not test therapeutic ultrasound equipment on oneself or others (as opposed to diagnostic ultrasound imaging, which can be used on volunteer models for training purposes under medical supervision).

\section{Patient Safety}

Ultrasound therapy machines are, of course, capable of causing substantial bioeffects; therefore, deliberate caution must be exercised to minimize injury for each patient. Patients should be fully informed of possible risks, as well as expected benefits.

\section{Quality Assurance}

Ultrasound therapy machines are typically complex and subject to deterioration or failure. Each machine should be monitored and tested on a regular basis for safe operation and verification of appropriate ultrasonic fields to ensure efficacious treatment.

\section{Accumulating Biological Effects}

Although no cumulative dose has been defined for any ultrasound therapy, unwanted bioeffects such as scarring from burns and vascular injury that occur during treatment can accumulate with repeated treatments, and this possibility should be anticipated. For example, animal studies show permanent loss of functional renal mass with each lithotripsy; therefore, recurrent treatments add injury to already impaired kidneys.

\section{Risk to Benefit Ratios}

The benefits and potential risks associated with different therapeutic ultrasound methods vary widely and should be appreciated by the operator. For example, physical therapy ultrasound appears to have a low risk of harm in the hands of skilled physical therapists, but the expectation of a therapeutic benefit is also low. Lithotripsy, in contrast, has the tremendous benefit of noninvasively treating a serious disease, which previously required major surgery, but it also has a risk of severe hemorrhage and longer-term kidney injury.

\section{Safety Research}

The search for new applications of this powerful tool should be pursued carefully, with thorough testing in appropriate animal models to identify possible human adverse events before clinical trials begin. Accurate and precise evaluation of acoustic fields in water and in situ should follow exposimetry and dosimetry procedures and numerical modeling previously recognized in the ultrasound literature. Means for monitoring heating or secondary mechanisms, such as acoustic cavitation, should be in place. Furthermore, to ensure optimum patient benefits from therapeutic ultrasound, dedicated research should continually pursue better and safer methods to enhance present therapies and therapy monitoring. 


\section{American Institute of Ultrasound in Medicine Bioeffects Committee Members}

Timothy Bigelow, PhD, Chair; Gregory Czarnota, $\mathrm{PhD}$, $M D$, Vice Chair; Jacques Abramowicz, MD; Michael Bailey, PhD; Andrew Brayman, PhD; Charles Church, PhD; Cheri Deng, PhD; Kullervo Hynynen, $\mathrm{PhD}$; Kolios, $\mathrm{PhD}$; Inder Makin, PhD; Thomas Nelson, PhD; Michael Oelze, PhD; Jean Lea Spitz, MPH, RDMS; Marvin Ziskin, MD. Resource members: John Abbott, PhD; Lori Barr, MD; Stephen Bly, PhD; Paul Carson, PhD; Edwin Carstensen, MS, PhD; Floyd Dunn, PhD; Peter Edmonds, PhD; Gerald Harris, PhD; Christy Holland, PhD; Christopher Merritt, MD; Douglas Miller, PhD; Wesley Nyborg, PhD; Narendra Sanghvi, MSEE; Thomas Szabo, PhD; Jinxing Tan, PhD; Kai Thomenius, PhD. Liaison Members: Jennifer Bagley, MPH, RDMS, RVT; Stanley Barnett, MSc, PhD; Samuel Nagle; Gail ter Haar, MA, DSc, MSc, PhD; Shahram Vaezy. Executive Committee liaison: J. Brian Fowlkes, PhD. Board of Governors liaison: Dev Maulik, $M D, P h D$.

\section{References}

1. Lehmann JF. The biophysical basis of biologic ultrasonic reactions with special reference to ultrasonic therapy. Arch Phys Med Rehabil 1953; 34:139-151.

2. Fry WJ, Mosberg WH Jr, Barnard JW, Fry FJ. Production of focal destructive lesions in the central nervous system with ultrasound. J Neurosurg 1954; 11:471-478.

3 Newell JA. Ultrasonics in medicine. Phys Med Biol 1963; 18:241-264.

4. Wells PN. Ultrasonics in medicine and biology. Phys Med Biol 1977; 22:629-669.

5. Kremkau FW. Cancer therapy with ultrasound: a historical review. J Clin Ultrasound 1979; 7:287-300.

6. Robertson VJ, Baker KG. A review of therapeutic ultrasound: effectiveness studies. Phys Ther 2001; 81:1339-1350.

7. Samulski TV, Grant WJ, Oleson JR, et al. Clinical experience with a multielement ultrasonic hyperthermia system: analysis of treatment temperatures. Int J Hyperthermia 1990; 6:909-922.

8. Tempany CMC, Stewart EA, McDannold N, Quade B, Jolesz F, Hynynen K. MRI-guided focused ultrasound surgery (FUS) of uterine leiomyomas: a feasibility study. Radiology 2003; 226:897-905.

9. Burgess SE, Silverman RH, Coleman DJ, et al. Treatment of glaucoma with high-intensity focused ultrasound. Ophthalmology 1986; 93:831838.

10. Klingler HC, Susani M, Seip R, Mauermann J, Sanghvi N, Marberger MJ. A novel approach to energy ablative therapy of small renal tumours: laparoscopic high-intensity focused ultrasound. Eur Urol 2008; 53:810 816.
11. Ninet J, Roques X, Seitelberger R, et al. Surgical ablation of atrial fibrillation with off-pump, epicardial, high-intensity focused ultrasound: results of a multicenter trial. J Thorac Cardiovasc Surg 2005; 130:803-809.

12. Alam M, White LE, Martin N, Witherspoon J, Yoo S, West DP. Ultrasound tightening of facial and neck skin: a rater-blinded prospective cohort study. JAm Acad Dermatol 2010; 62:262-269.

13. Weizer AZ, Zhong P, Preminger GM. New concepts in shock wave lithotripsy. Urol Clin North Am 2007; 34:375-382.

14. Lowe G, Knudsen BE. Ultrasonic, pneumatic and combination intracorporeal lithotripsy for percutaneous nephrolithotomy. J Endourol 2009; 23:1663-1668.

15. Haake M,Buch M, Schoellner C, et al. Extracorporeal shock wave therapy for plantar fasciitis: randomised controlled multicentre trial. BMJ 2003 327:75.

16. Packer M, Fishkind WJ, Fine IH, Seibel BS, Hoffman RS. The physics of phaco: a review. J Cataract Refract Surg 2005; 31:424-431.

17. Mann MW, Palm MD, Sengelmann RD. New advances in liposuction technology. Semin Cutan Med Surg 2008; 27:72-82.

18. Koch C, Borys M, Fedtke T, Richter U, Pöhl B. Determination of the acoustic output of a harmonic scalpel. IEEE Trans Ultrason Ferroelectr Freq Control 2002; 49:1522-1529.

19. Parikh S, Motarjeme A, McNamara T, et al. Ultrasound-accelerated thrombolysis for the treatment of deep vein thrombosis: initial clinical experience. J Vasc Interv Radiol 2008; 19:521-528.

20. Smith NB.Applications of ultrasonic skin permeation in transdermal drug delivery. Expert Opin Drug Deliv 2008; 5:1107-1120.

21. Gebauer D, Mayr E, Orthner E, Ryaby JP. Low-intensity pulsed ultrasound: effects on nonunions. Ultrasound Med Biol 2005; 31:1391-1402.

22. Nyborg, WL, Carson PL, Carstensen EL, et al. Exposure Criteria for Medical Diagnostic Ultrasound, II: Criteria Based on All Known Mechanisms. Bethesda, MD: National Council on Radiation Protection and Measurements; 2002. Report 140 .

23. Fowlkes JB; Bioeffects Committee of the American Institute of Ultrasound in Medicine. American Institute of Ultrasound in Medicine consensus report on potential bioeffects of diagnostic ultrasound: executive summary. J Ultrasound Med 2008; 27:503-515.

24. Alves EM, Angrisani AT, Santiago MB. The use of extracorporeal shock waves in the treatment of osteonecrosis of the femoral head: a systematic review. Clin Rheumatol 2009; 28:1247-1251.

25. Hundt W, Yuh EL, Bednarski MD, Guccione S. Gene expression profiles, histologic analysis, and imaging of squamous cell carcinoma model treated with focused ultrasound beams. Am J Radiol 2007; 189:726-736.

26. Silberstein J, Lakin CM, Parsons JK. Shock wave lithotripsy and renal hemorrhage. Rev Urol 2008; 10:236-241.

27. Machet L, Boucaud A. Phonophoresis: efficiency, mechanisms and skin tolerance. Int J Pharm 2002; 243:1-15.

28. Baker KG, Robertson VJ, Duck FA. A review of therapeutic ultrasound: biophysical effects. Phys Ther 2001; 81:1351-1358. 
29. Alexander LD, Gilman DR, Brown DR, Brown JL, Houghton PE. Exposure to low amounts of ultrasound energy does not improve soft tissue shoulder pathology: a systematic review. Phys Ther 2010; 90:14-25.

30. Sapareto SA, Dewey WC. Thermal dose determination in cancer therapy. Int J Radiat Oncol Biol Phys 1984; 10:787-800.

31. Diederich CJ, Hynynen K. Ultrasound technology for hyperthermia. Ultrasound Med Biol 1999; 25:871-887.

32. Marchal C. Clinical trials of ultrasound hyperthermia. Ultrasonics 1992; 30:139-141.

33. Kong G, Braun RD, Dewhirst MW. Hyperthermia enables tumor-specific nanoparticle delivery: effect of particle size. Cancer Res 2000; 60:4440 4445.

34. Kennedy JE, Ter Haar GR, Cranston D. High-intensity focused ultrasound: surgery of the future? Br J Radiol 2003; 76:590-599.

35. Gliklich R, White WM, Barthe PG, Slayton MH, Makin IRS, Clinical pilot study of intense ultrasound (IUS) therapy to deep dermal facial skin and subcutaneous tissues. Arch Facial Plast Surg 2007; 9:88-95.

36. Evans KD, Weiss B, Knopp M. High-Intensity focused ultrasound (HIFU) for specific therapeutic treatments: a literature review.J Diagn Med Sonography 2007; 23:3119-3127.

37. Foley JL, Little JW, Vaezy S. Effects of high-intensity focused ultrasound on nerve conduction. Muscle Nerve 2008; 37:241-250.

38. Gelet A, Chapelon JY, Bouvier R, et al. Transrectal high-intensity focused ultrasound: minimally invasive therapy of localized prostate cancer. J Endourol 2000; 14:519-528.

39. Thüroff S, Chaussy C, Vallancien G, et al. High-intensity focused ultrasound and localized prostate cancer: efficacy results from the European Multicentric Study. J Endourol 2003; 17:673-677.

40. Jolesz F. MRI-guided focused ultrasound surgery. Annu Rev Med 2009; 60:417-430.

41. McDannold N, Clement GT, BlackP, JoleszF, Hynynen K. Transcranial magnetic resonance imaging-guided focused ultrasound surgery of brain tumors: initial findings in three patients. Neurosurgery 2010; 66:323-332.

42. Martin E,Jeanmonod D, Morel A, Zadicario E, Werner B. High-intensity focused ultrasound for noninvasive functional neurosurgery. Ann Neurol 2009; 66:858-861.

43. Hynynen K, Pomeroy O, Smith DN, et al. MR imaging-guided focused ultrasound surgery of fibroadenomas in the breast: a feasibility study. $R a-$ diology 2001; 219:176-185.

44. Gianfelice D, Khiat A, Amara M, Belblidia A, Boulanger Y. MR imagingguided focused US ablation of breast cancer: histopathologic assessment of effectiveness - initial experience. Radiology 2003; 227:849-855.

45. Gianfelice D, Gupta C, Kucharczyk W, Bret P, Havill D, Clemons M. Palliative treatment of painful bone metastases with MR imaging-guided focused ultrasound. Radiology 2008; 249:355-563.

46. Roujol S, Ries M, Quesson B, Moonen C, Denis de Senneville B. Realtime MR-thermometry and dosimetry for interventional guidance on abdominal organs. Magn Reson Med 2010; 63:1080-1087.

47. Chopra R, Tang K, Burtnyk M, et al. Analysis of the spatial and temporal accuracy of heating in the prostate gland using transurethral ultrasound therapy and active MR temperature feedback. Phys Med Biol 2009; 54:2615-2633.
48. Fedewa RJ, Carlson RF, Seip R, Sanghvi NT, Koch MO, Gardner TA Prediction of success for HIFU treatments of prostate cancer based on acoustic energy density. In: Ultrasonics Symposium, 2006. New York, NY: Institute of Electrical and Electronics Engineers; 2006:732-735.

49. Casper A, Liu D, Ebbini ES. Realtime control of multiple-focus phased array heating patterns based on noninvasive ultrasound thermography. IEEE Trans Biomed Eng 2012; 59:95-105.

50. Curiel L, Huang Y, Vykhodtseva N, Hynynen K. Focused ultrasound treatment of VX2 tumors controlled by local harmonic motion. Phys Med Biol 2009; 54:3405-3419.

51. Anand A, Kaczkowski PJ. Noninvasive determination of in situ heating rate using $\mathrm{kHz}$ acoustic emissions and focused ultrasound. Ultrasound Med Biol 2009; 35:1662-1671.

52. Canney MS, Khoklova V, Bessonova OV, Bailey MR, Crum LA, Shockinduced heating and millisecond boiling in gels and tissue due to high-intensity focused ultrasound. Ultrasound Med Biol 2010; 36:250-267.

53. Makin IR, Mast TD, Faidi WF, Runk MM, Barthe PG, Slayton MH. Miniaturized arrays for interstitial ablation and imaging. Ultrasound Med Biol 2005; 31:1539-1550.

54. Kinsey AM, Diederich CJ, Rieke V, et al. Transurethral ultrasound applicators with dynamic multi-sector control for prostate thermal therapy: in vivo evaluation under MR guidance. Med Phys 2008; 35:2081-2093.

55. Prat F, Lafon C, De Lima DM, et al. Endoscopic treatment of cholangiocarcinoma and carcinoma of the duodenal papilla by intraductal highintensity US: results of a pilot study. Gastrointest Endosc 2002; 56:909-915.

56. Schmidt B, Chun KR, Kuck KH, Antz M. Pulmonary vein isolation by high-intensity focused ultrasound. Indian Pacing Electrophysiol J 2007; 7:126-133.

57. Moreno-Moraga J, Valero-Altés T, Riquelme AM, Isarria-Marcosy MI, Royo de la T. Body contouring by noninvasive transdermal focused ultrasound. Lasers Surg Med 2007; 39:315-323.

58. Fatemi A. High-intensity focused ultrasound effectively reduces adipose tissue. Semin Cutan Med Surg 2009; 28:257-262.

59. White WM, Makin IRS, Barthe PG, Slayton MH, Gliklich R. Selective creation of thermal injury zones within the superficial musculoaponeurotic system using intense ultrasound therapy: a new target for noninvasive facial rejuvenation. Arch Facial Plast Surg 2007; 9:22-29.

60. Hynynen K, Chung AH, Colucci V, Jolesz FA. Potential adverse effects of high-intensity focused ultrasound exposure on blood vessels in vivo. Ultrasound Med Biol 1996; 22:193-201.

61. Rove KO, Sullivan KF, Crawford ED. High-intensity focused ultrasound: ready for primetime. Urol Clin North Am 2010; 37:27-35.

62. Borchert B, Lawrenz T, Hansky B, Stellbrink C. Lethal atrioesophageal fistula after pulmonary vein isolation using high-intensity focused ultrasound (HIFU). Heart Rhythm 2008; 5:145-148.

63. Neven K, Schmidt B, Metzner A, et al. Fatal end of a safety algorithm for pulmonary vein isolation with use of high-intensity focused ultrasound. Circ Arrhythm Electrophysiol 2010; 3:260-265.

64. Jung SE, Cho SH, Jang JH, Han JY. High-intensity focused ultrasound ablation in hepatic and pancreatic cancer: complications. Abdom Imaging 2011;36:185-195.

65. McAteer JA, Bailey MR, Williams JC Jr, Cleveland RO, Evan AP. Strate- 
gies for improved shock wave lithotripsy. Minerva Urol Nefrol 2005; 57:271-287.

66. Eisenmenger W. The mechanisms of stone fragmentation in ESWL. Ultrasound Med Biol 2001; 27:683-693.

67. Sapozhnikov OA, Maxwell AD, MacConaghy B, Bailey MR. A mechanistic analysis of stone fracture in lithotripsy. J Acoust Soc Am 2007; 121:1190-1202.

68. Pishchalnikov YA, Neucks JS, VonDerHaar RJ, Pishchalnikova IV, Williams JC Jr, McAteer JA. Air pockets trapped during routine coupling in dry head lithotripsy can significantly decrease the delivery of shock wave energy. JUrol 2006; 176:2706-2710.

69. Evan AP, McAteerJA. Effects of shock wave lithotripsy. In: Coe Fl, Favus M, Pak C, Parks J, Preminger G (eds). Kidney Stones: Medical and Surgical Management. Philadelphia, PA: Lippincott-Raven; 1996:549-570.

70. Koga H, Matsuoka K, Noda S, Yamashita T. Cumulative renal damage in dogs by repeated treatment with extracorporeal shock waves. Int J Urol 1996; 3:134-140.

71. Evan AP, Willis LR, Lingeman JE, McAteer JA. Renal trauma and the risk of long-term complications in shock wave lithotripsy. Nephron 1998; 78:1-8.

72. Janetschek G, Frauscher F, Knapp R, Höfle G, Peschel R, Bartsch G. Newonset hypertension after extracorporeal shock wave lithotripsy: age-related incidence and prediction by intrarenal resistive index. J Urol 1997; 158:346-351

73. Krambeck AE, Handa SE, Evan AP, Lingeman JE. Brushite stone disease as a consequence of lithotripsy? Urol Res 2010; 38:293-299.

74. Krambeck AE, Gettman MT, Rohlinger AL, Lohse CM, Patterson DE, Segura JW. Diabetes mellitus and hypertension associated with shock wave lithotripsy of renal and proximal ureteral stones at 19 years of follow-up.J Urol 2006; 175:1742-1747.

75. Pace KT, Ghiculete D, Harju M, Honey RJ; University of Toronto Lithotripsy Associates. Shock wave lithotripsy at 60 or 120 shocks per minute: a randomized, double-blind trial. JUrol 2005; 174:595-599.

76. Handa RK, Bailey MR, Paun M, et al. Pretreatment with low-energy shock waves induces renal vasoconstriction during standard shock wave lithotripsy (SWL): a treatment protocol known to reduce SWL-induced renal injury. BJU Int 2009; 103:1270-1274.

77. Kim SC, Matlaga BR, Tinmouth WW, et al. In vitro assessment of a novel dual-probe ultrasonic intracorporeal lithotriptor.JUrol 2007; 177:13631365.

78. Noor Buchholz NP. Intracorporeal lithotripters: selecting the optimum machine. BJU Int 2002; 89:157-161

79. Boucaud A. Trends in the use of ultrasound-mediated transdermal drug delivery. Drug Discov Today 2004; 9:827-828.

80. Pitt WG, Husseini GA, Staples BJ. Ultrasonic drug delivery: a general review. Expert Opin Drug Deliv 2004; 1:37-56.

81. Mitragotri S, Kost J. Low-frequency sonophoresis: a review. Adv Drug Deliv Rev 2004; 56:589-601.

82. Farinha A, Kellogg S, Dickinson K, Davison T. Skin impedance reduction for electrophysiology measurements using ultrasonic skin perme- ation: initial report and comparison to current methods. Biomed Instrum Technol 2006; 40:72-77.

83. Mitragotri S, Edwards DA, Blankschtein D, Langer R.A mechanistic study of ultrasonically-enhanced transdermal drug delivery.J Pharm Sci 1995; 84:697-706.

84. Siegel RJ, Luo H. Ultrasound thrombolysis. Ultrasonics 2008; 48:312320.

85. Daffertshofer M, Gass A, Ringleb P, et al. Transcranial low-frequency ultrasound-mediated thrombolysis in brain ischemia: increased risk of hemorrhage with combined ultrasound and tissue plasminogen activatorresults of a phase II clinical trial. Stroke 2005; 36:1441-1446.

86. Hitchcock KE,Holland CK. Ultrasound-assisted thrombolysis for stroke therapy: better thrombus break-up with bubbles. Stroke 2010; 4(suppl):S50-S53.

87. Tufail Y, Matyushov A, Baldwin N, et al. Transcranial pulsed ultrasound stimulates intact brain circuits. Neuron 2010; 66:681-694.

88. Tinkov S, Bekeredjian R, Winter G, Coester C. Microbubbles as ultrasound-triggered drug carriers. J Pharm Sci 2009; 98:1935-1961.

89. Unger EC, Porter T, Culp W, Labell R, Matsunaga T, Zutshi R. Therapeutic applications of lipid-coated microbubbles. Adv Drug Deliv Rev 2004; 56:1291-1314.

90. Ferrara K, Pollard R, Border M. Ultrasound microbubble contrast agents: fundamentals and application to gene and drug delivery. Annu Rev Biomed Eng 2007; 9:415-447.

91. Vykhodtseva N, McDannold N, Hynynen K. Progress and problems in the application of focused ultrasound for blood-brain barrier disruption. Ultrasonics 2008; 48:279-296.

92. Tartis MS, McCallan J, Lum AF, et al. Therapeutic effects of paclitaxelcontaining ultrasound contrast agents. Ultrasound Med Biol 2006; 32:1771-1780

93. Miller DL. Ultrasound-mediated gene therapy. In: Wu J, Nyborg WL (eds). Emerging Therapeutic Ultrasound. Singapore: World Scientific Publishing Co; 2006:69-130.

94. Kieran K, Hall TL, Parsons JE, et al. Refining histotripsy: defining the parameter space for the creation of nonthermal lesions with high-intensity, pulsed focused ultrasound of the in vitro kidney. J Urol 2007; 178:672676.

95. Xu Z, Raghavan M, Hall TL, Mycek MA, Fowlkes JB. Evolution of bubble clouds induced by pulsed cavitational ultrasound therapy: histotripsy IEEE Trans Ultrason Ferroelectr Freq Control 2008; 55:1122-1132.

96. Apfel RE. Acoustic cavitation. In: Edmonds PD (ed). Ultrasonics. Methods of Experimental Physics. Vol 19. New York, NY: Academic Press; 1981:355-411.

97. Hamilton M, Blackstock D. Nonlinear Acoustics. San Diego, CA: Academic Press; 1998.

98. Lewin P, Ziskin M. Ultrasonic Exposimetry. Boca Raton, FL: CRC Press; 1992.

99. Harris GR. Progress in medical ultrasound exposimetry. IEEE Trans Ultrason Ferroelectr Freq Control 2005; 52:717-736 
Miller et al—Therapeutic Ultrasound Applications and Safety Considerations

100. Shaw A, ter Haar G. Requirements for Measurement Standards in High-Intensity Focused Ultrasound (HIFU) Fields. Teddington, England: National Physical Laboratory; 2006. Report DQL AC 015.

101. Shaw A, Hodnett M. Calibration and measurement issues for therapeutic ultrasound. Ultrasonics 2008; 48:234-252.

102. Hwang JH, TuJ, Brayman AA, Matula TJ, Crum LA. Correlation between inertial cavitation dose and endothelial cell damage in vivo. Ultrasound Med Biol 2006; 32:1611-1619.

103. McDannold N, Vykhodtseva N, Hynynen K. Targeted disruption of the blood-brain barrier with focused ultrasound: association with cavitation activity. Phys Med Biol 2006; 51:793-807. 